\title{
Citation as a Stimulus to Boost Students' Communication Skills at the English Lessons
}

\author{
Aida G. Sadykova ${ }^{1}$, Marianna E. Yashina ${ }^{1} \&$ Alina D. Sharafieva ${ }^{1}$ \\ ${ }^{1}$ Kazan (Volga Region) Federal University, Kazan, Russia \\ Correspondence: Marianna E. Yashina, Kazan (Volga Region) Federal University, Kazan, Russia. Tel: \\ 795-0314-2977. E-mail: ilona141199@yandex.ru
}

Received: August 26, 2014 Accepted: October 20, 2014 Online Published: November 19, 2014

doi:10.5539/elt.v7n12p12 URL: http://dx.doi.org/10.5539/elt.v7n12p12

\begin{abstract}
The study contemplates significance of using citation at the English lessons by exposing its advantages. Quotations represent the enormous linguistic variety, which discloses the modern language that unambiguously assists students to develop skills of oral speech. Special attention is paid to the experimentconducted at the series of lessons in order to enhance students' linguistic interest, incentive and aimed at the development and improvement of communicative competence.
\end{abstract}

Keywords: authenticity, citation, communication skill, communicative competence, linguistic interest

\section{Introduction}

In recent years, an issueof the application modern methods and models of teaching foreign languages in secondary schools is on the agenda. Therefore, educators try to implement effective useof new methods in order to improve the quality of teaching foreign languages, the formation and development of thestudents' communicative culture. Actual experience shows that sometimes the teacher of English as a Foreign Language (EFL) in Russia sets pedagogical tasks in accordance with the disclosure of certain educational material but not on the basis of the possibilities and prospects of students' development. Consequently, the teacher along with traditional methods should use such methods and means that would ensure the formation of communication skills and givea great opportunity for active oral practice of each individual student. In this case, citation as a pedagogical means is one of the most effective ways to make the lesson intense and extraordinary, which certainly contributes to better memorization and encourages the development, formation and improvement of communication skills.

Based on the above stated, the modern pedagogical theory and practice needs to resolve the contradictions between:

- Passive ability to perceive and the ability to understand and produce speech;

- Increasing interest of students to the culture of other countries, to their lifestyle and their desire to enter into close intercommunication with foreign peers and content of the process of teaching foreign languages in secondary schools.

The purpose of the study is to identify and substantiate efficiency of citation at foreign language lessons.

Object of the study: the process of learning a foreign language in secondary schools.

Subject of the study: the use of citation in receiving, training and learning activities of students at English lessons.

Hypothesis of the study lies in the assumption that the use of citation at English lessons contributes to the formation of communicative competence, the development of linguistic interest and motivationof students.

\section{Methods}

In order to test the hypothesis, there were used the following methods:

Theoretical (analysis of psycho-pedagogical, linguistic, methodological literature on effective use of citation at foreign language lesson, comparison and generalization of teaching experience, analysis of terminology, classification); 
Empirical (pedagogical supervision, testing, discussion, pedagogical experiment);

Experimental (ascertaining slice, organizing and conducting a formative experiment);

Statistics (mathematical processing and evaluation of the results obtained during the experiment).

\section{Communicative Orientation}

Observations of recent years reveal a steady tendency that the basis of teachingforeign languages is communicative. The result is that during the process of teaching English a teacher needs to use and combine different methods and techniques in order to develop, enhance and improve communication skills. Citation as a means makes an invaluable contribution to the teaching and learning process in the study of the English language, has a positive effect on the motivation of students and makes the lesson interesting that inspires students to improve English language skills and use them in practice. What is the quotation and what place does it occupy in the structure of the English language lesson? Citation involves the use of the main types of inspirational phrases - aphorisms, proverbs and sayings that can be applied at different stages of the lesson and at all levels of education (elementary, middle, senior) with differentstudents' levels of language depending on what goals the teacher and what skills he wants to form in their students at this stage of training.

A characteristic feature of the aphorism is considered originality of thought. Aphorism expresses like proverb any rules of life experience, but in contrast to it, expresses often subjective and often controversial opinion.

According to many studies, expressiveness of aphorism increases with thedecrease number of words, about 3/4 of all aphorisms consists of only three to five words.

Structurally aphorism is often based on the antithesis of different varieties. Most of aphorisms are based on the paradox that is the junction of the incongruous. Aphorism, owing to its paradoxicality, influences the feelings and the mind of the student. The paradoxical nature - one of the main means of expressiveness in aphorisms. Statement that conveys an aphorism is often illogical, and to comprehend its meaning, a student needs to spend a certain logical work. Whereby exercises using aphorisms become an important step to work with students at English lessons, increasing their activity and efficiency in the classroom, as they contribute to the incorporation of games and competitions in the process of improvement the language.

Adages give rich spiritual food for self-reflection. Indeed, sometimes quite brief and informative statements cause train of thoughts and associations. Knowledge and reading of aphorisms is not only intellectual pleasure, but also one of the powerful means of developing the culture of speech and thought. They sharpen the mind, grind and have an emotional impact on the listener.

Besides, according to the research of psychologists, the utterance of aphorisms in special psychophysical periods of learners' life has contributed significantly to the intensification of educational and cognitive process. They were indispensable means in teaching foreign languages, for example, the Latin language, even in medieval Europe. Nowadaysalmost every foreign language course quite often refers to their use. Not without reason. It should be noted that the quotation reflects the foreign speaker's outlook. The study of quotations in English allows students to learn the spoken language, receive extralinguistic information about the author, his line of work.

It is essential to emphasize that at English lessons they can be used not only as a material for storing and correct employment, but also as a means of forming and control complex of communication skills: vocabulary and grammar, reading, listening, speaking and writing. Unconditionally, it is impossible to learn the languageonly in English proverbs. However, proverbs and wise thoughts in the form of aphorisms serve a good incentive for better assimilation of the language, causing the linguistic interest of students. The use of quotes at English lessons, primarily serves as a means to stimulate students to learn English, as well as forming an integral part of the communicative competence of students. They make students think, inspire, learn to express their own opinions in English.

Citation as a means of learning can be used as any kind of verbal techniques in the classroom: the story, lecture, explanation, discussion, conversation.

The main purpose of learning a foreign language is the formation of communicative competence, that is, the willingness and ability to carry out cross-cultural communication in a foreign language with native speakers. Communicative competence involves the knowledge and skills necessary to understand the foreign language dialogue and generating its own model of verbal behavior, adequate targets in accordance with the proper situation.

It is known that the traditional organization of a series of lessons in a foreign language within the same theme 
includes: an introduction and initial consolidation of linguistic material (phonetics, vocabulary, grammar); its activation and refinement in speech and writing, monologues and dialogues, and proper control of its acquisition by teachers. Such cyclicity observed in the study of each new topic. Moreover, each following cycle departs from the previous and deepens and expands the new content, requiring the use of the accumulated knowledge and skills in a new environment. Nevertheless, as experience shows, this technique lacks of sufficient motivation. In addition, the gap between the knowledge and skills of traineeswas revealed, there are cases when they know the rules and cannot take advantage of them, know the words and cannot use them, causing the need for new methods of providing for the development of communication skills that support the motivation to learn a foreign language. By such methodscitationis implied.

Currently, almost every educational-methodical complex in the English language presents specially designed exercises that contain proverbs («Proverbs and sayings»), contributing to all kinds of students developing aspects of language (phonetics, vocabulary, grammar), and that is important, one of the most important types of speech activity, speaking. Proverbs and Sayings are a useful material for teaching students how one idea can be presented in different words. They are indispensable in teaching monologues and dialogues, making the speech expressive, lively, so the topic under consideration seems to us topical.

In order to form a communicative speech abilities functional—communication tasks exist that involve such tasks as: detection of the missing elements in the texts and images, the construction of clear instructions to communication partner for the successful fulfilment of the assignment, the implementation of finding answers to questions through combining all of the factors known to other participants. For example, a striking example of functional-communicative tasks may serve restoring logical sequence fragments of proverbs (e.g, the teacher reads the beginning of a proverb, and students must complete: A forced kindness deserves ... no thanks).

Unlike verbal skills, which are inherent in the stereotype, communicative speech skills are creative in nature as in different situations of everyday communication, which each time for the student will be new, there is a need for re-selectionfor appropriate linguistic means. Consequently, methods of training communicative speech skills should differ from the methods of teaching speech skills. The notion "communicative action" does not equate to the concept of "communicative exercise", it is much broader. In particular, unlike communicative actions here students' communicative freedom and self-realization are brought to the fore. During communicative activities, each student gets an opportunity to realize himself in a communicative way as a linguistically interesting personality. The effectiveness of these measures is based on the fact that the communicants, in other words, students are placed in an environment in which they have to say on a given subject at the moment of the lesson. For successful implementation of communicativeactivities, two related factors are of paramount importance: interest in the subject and the maximal involvement of students in its active discussion. In this connection, the lessonswith the usage of citation are one of the glaring examples of the fulfilment of communication activities. Students' interest is guaranteed by the fact that aphorisms, proverbs and sayings are selected in accordance with the students' interest, which in turn, promotes the involvement into the debate, discussion quotations on a particular topic.

Communicative activities help to overcome the great difficulty - the implementation of speech intentions with native speakers. In the learning environment, students usually express in a sample analogy or under the influence of the teacher. In real situations with native speakers student's speech intention most often, as evidenced by observations, takes unnatural form or even is blocked.

When students write or complete other assignments that they perceive as meeting a real and immediate need, the quality of their work is superior to what they typically produce. These are the kinds of assignments that Edelsky (1989) calls "authentic". During these assignments, students are using language naturally to fulfill real purposes, and for that reason, the assignments are meaningful to the students (Edelsky, 1989).

A goal of teachers who follow principles for success is to involve students in activities that are meaningful and have a clear purpose. For an assignment or activity to be meaningful, it must be understood by the student. In the case of second language students, some assignments are not meaningful simply because the students don't understand the language of the assignment. They are not receiving "comprehensible input" (Krashen, 1982).

Real-life situations are the starting point for the implementation of communication activities. That is why in the learning process the usage of citationis the most appropriate, providing real communication in educational settings. Application of communicative activities in the classroom promotes elimination of language barriers in the process of direct real communication. It is increasingly achieved by complete exclusion of the Russian language during the lesson (especially at intermediate and advanced levels). Many communicative activities include competitive nature that defines communicative orientation sessions, and allows the teacher to stimulate 
and motivate students to untrained statement quite easy.

From lesson to lesson the children accumulate a certain baggage of proverbs and sayings, whereby it becomes possible to offer a variety of creative activities with them and all kinds of game techniques to stimulate the activity of students in the classroom. Indeed, many teachers familiar with the situation, when onlythe same 5-6 peopleworkin a group of 12-15 students.

Obvious examples of communicative activities include the following tasks:

$\checkmark \quad$ Replace some nouns in well-known proverbs and comment:

Money makes the world go round (not Love)

Too many students spoil the lesson (instead of cooks and broth)

$\checkmark \quad$ Advise partner, to paraphrase the saying, for example:

Measure twice and cut once. - Measure twice, cut once. Before making any decision, think it over. Weigh all the pros and cons. You won't have a chance to change anything, it will be too late.

$\checkmark \quad$ Think of advertisement using proverbs:

For example: Eat the grapes, not the vine — grapes better than wine:

Vines are our business, grapes are yours. or We'll care after the vines, you'd better eat the grapes.

Moreover, the introduction of quotations in the English language training is the most productive with the development of cognitive abilities of students. Memorizing them by heart, students learn new vocabulary, which, in the course of further study can be used as active vocabulary. It should be noted that their memorization easier due to different harmonies, rhythm and rhyme.

Proponents of direct methods have argued that repeated appeals to the same phrases in certain situations affect the alignment of grammatical structures. Since, as a rule, new words are stored in memory for longer insentences having a complete thought.

Remembering proverbs not only develops students' memory, but also allows them to polish up the ability to perform adequately the selection of lexical units. Appropriate and correct application of the proverbial speech gives a unique, special expressiveness and originality. So far as proverbs have no temporallimits, they will never lose its relevance. At the same time, their study is an additional source of regional geographic knowledge, assisting to develop a socio-cultural competence, and it is also an integral part of learning English.

Based on the above stated, it can be ascertained that the use of citation in the practice of teaching English will certainly be conducive to a better proficiency of the subject, as they have a great potential in learning a foreign language at school. Learning with communicative tasks and activities gives lesson creative nature, heighten interest. Application of proverbs and sayings in the classroom helps students to engage in dialogue, obtaining information about the syntax, grammar, and phraseology, supplement the information of the country of the target language. Possession of knowledge of proverbs and sayings allows students to perceive correctly by hearing the voice message, interpret and react to them, to express their views so as to be understood by the partner in communication, which eventually will determine the success of communication.

\section{Content-Based Language Teaching}

Halliday (1984) pointed out that children learn language, they learn through language, and they learn about language (Halliday, 1984). All three aspects develop simultaneously in classes where language is taught through academic content. It is this idea of learning language through meaningful language use that is the basis for content-based instructional methods for English language learners. Because people learn language as they use it, it is logical to have them learn English as they study meaningful content, rather than to have them study the English language as a separate subject apart from meaningful content.

Brinton, Snow, and Wesche (1989) present five rationales for integrating the teaching of language and content. First, this approach provides the language forms students need. If a student is interested in politics, the best way for a student to learn politic concepts is by reading books, quotes of politicians and discussing politics. As students study politics, they learn the vocabulary and language structures associated with that subject area. Secondly, even if the content area of study involves language that is difficult, students are more apt to be motivated to learn because of their interest in the subject matter.

A third rationale for teaching language through content is that this approach ensures that teachers build on the background knowledge of the students. Most students have some knowledge of the subject areas that interest 
them. Fourth, this approach ensures that lessons include contextualized language use rather than fragmented studies of usage. That is, students are involved with language in the context of authentic texts instead of doing exercises or drills on language forms presented out of context. (Brinton, Snow, \& Wesche, 1989)

Brinton et al. (1989) argue that for teachers to take this approach they must use authentic texts, those that are not specifically designed for language teaching but, instead, are written as literature to be enjoyed, or as informational material related to some subject area. In this case, quotes concerning certain themes may serve as considerable material to focus lessons on. Teacher's task is to select particular language structures, vocabulary, meaning found in the quotation. This approach begins with learner needs and interests. It allows teachers to find creative ways to make content areas understandable for students whose English proficiency is limited (Brinton et al., 1989).

A final rationale for teaching language through content comes from second language acquisition theory. Krashen (1982) argues that students acquire language when they receive comprehensible input that contains items slightly beyond their present level of proficiency. The input can come from reading or from listening. As they study different content areas by reading quotations in English, discussing the content, and writing about the subject area, students naturally acquire English (Krashen, 1982).

It is important to emphasize that among many general subjects, the subject of "foreign language" occupies an important place in the education of students. We are convinced that a foreign language is a significant formative factor necessary for the overall development of a student and the full realization of his abilities and opportunities in an adult independent life.

Teaching foreign languages in secondary school is comprehensive implementation of practical, educational, educative and developmental goals. In our opinion, the use of aphorisms allows to combine and fully realize the all goals of foreign language teaching.

The practical goal of learning a foreign language is to build skills of speaking and writing in a foreign language, which provide the necessary cognitive and communicative needs of students at each level of education and the possibility of their initiation to the cultural values of the target language media. A language teacher more than any other teacher has to influence the emotional state of students and stimulate interest in learning activities. Taking into account the specificity of the subject, the rational organization of the lesson, the skilful use of aphorisms, profound professional knowledge of the teacher can cause the interest of students to polish up a foreign language. Aphorism can be a support for the deployment of semantic debate. For example, studying at the senior stage education theme «Personal qualities» a lesson can begin with an aphorism of famous singer Bob Marley «You never know how strong you are, until being strong is your only choice». The teacher can organize a series of questions on this topic:

1) Have you ever been in a no-win situation?

2) How did you succeed in finding way out of that situation?

3) Are you strong? Can you surmount all obstacles despite everything?

4) Which qualities did stand you in good stead in this case? etc.

The teacher can work out the necessary pre useful expressions on the subject, for example: a no-win situation, strength of mind, to stand somebody in good stead, a way out of the situation.

The teacher may ask students to give examples from personal experience, in accordance with the aphoristic statement. Usually during controlled discussion portrait of personality traits outlines based on their own personal examplesand students come to the conclusion about the significance of the potential inherent in each of them.

The educative goal of learning is to form by means of a foreign language active personality, which is characterized by conviction, a sense of patriotism, culture, intercultural communication, independence, hard work and respect for other mentalities. In this case, every foreign language teacher necessarily raises the question: "In addition to performing a specific program (lessons, assessment tests), am I promote mental enrichment of students, whether help them to become highly educated people?" An English teacher has a greater advantage over the others - he can exercise "the education of the senses" through the application of aphorisms, which creates an excellent opportunity to combine linguistic analysis with knowledge of spiritual values. Classic aphorism contains concepts such as the soul, hope, destiny, faith, knowledge, love, beauty, goodness, and evil, friendship, reflecting the spiritual quest and thought processes.

As for the educational purpose of learning a foreign language, it pursues familiarizing students with the culture of the target language country, the formation of the linguistic competence of the students, their outlook and 
erudition. Foreign language should become a significant tool for the implementation of interdisciplinary connections, familiarizing students with various spheres of human activity: art, history, and literature. Introduction to the language is a kind of introduction to the culture of the people who created it. Language has two main functions: communicative, as it is through communication and language is cumulative, as the language keeps people's culture - its carrier. It should be noted that the great people of England, America - writers, poets, scientists, philosophers are outstanding representatives of their people, and their sayings to help students better understand their mentality and traditions.

Educational purpose of foreign language teaching is expressed in the development of language skills, constant motivation to learn a foreign language and learning activities in general, the culture of verbal communication.

To promote a culture of verbal communication students need to consider the features that aphorism performs in communication, namely:

- Persuasive

- Representative

- The password

Performing persuasive function involves the use of the aphorism to convince communicative partner in the justice of their opinions. Password-function - this function to find the contact and confirmation of the author and addressee to one intellectual, political, or other age group. Quotations are used to attract the audience's attention and positive self-presentation. In this case, the password function is accompanied by a representative function (stand out from the others).

From a linguistic point of view aphorism is a full text and can serve as material for different kinds of work: individual, front, team, group, independent. According to linguists, even minimal literary text, which consists of a single sentence, is a three-dimensional field for discussion and reflection. Aphorisms in the classroom can perform a range of tasks. Firstly, knowledge of the aphoristic fund facilitates memorization of complete grammatical and syntactical structures. Secondly, aphorisms are the basis for the replenishment of vocabulary, and for mastering a variety of cliches and comparative turns of speech. For example: «Difficulties strengthen the mind, as labour does the body» (Seneca).

Thirdly, due to the special phonostylistic organization aphorisms are often performed in a poetic form. Memorization helps to improve their pronunciation skills, to intone phrases in Englishcorrectly and clearly, to form expressive skills, facing the audience speech. To cap it all, the study of aphorisms allows students to broaden their outlook and learn cultural values, priorities, history and habits of other people.

Reading aphorisms is a powerful means of forming the culture of speech and thought. Most aphorisms appear to students as a mirror in which they can see themselves from different sides. Some aphorisms make them laugh, some probably shame, some excite, tune into deep meditation, cause a sincere conversation with himself, make students think of the moral consciousness and, perhaps, to encourage corrective action. They contribute to understanding the role of personality in the world, helping to further consideration of the picture of public morality. Aphorisms have a remarkable ability to exist outof the context. Appointment of many aphorisms is not only in answering the questions about the meaning of life, but also in preventing erroneous. Educational and training opportunities for aphoristic arsenal of traditional training are essential ethnopedagogical content of education.

Compactness, a variety of themes and deep meaning of the content allow educator to enable aphoristic statements in any speech situation, monologue or dialogue. Important value of the aphorism that it is a symbol, a sign that shows all the things taught by pedagogical tradition, and that is important, actualizes in speech as the need arises, defining a model of behavior and affecting the expression of student's personality.

Thus, aphorisms have the ample opportunities in the process of moral education of pupils and a high degree of motivation in learning, being a necessary and versatile teaching tool. They make learning more fun and interesting. Furthermore, the use of aphorisms in the learning process allows solving important pedagogical issues: allows teachers and students to understand each other, helps stimulate cognitive and creative abilities. Students learn to compare, analyze, synthesize, summarize, and make inferences.

All this allows the use of aphorisms at the English lessons in accordance with a specific theme of the lesson, being simultaneously the source of the system of human values, knowledge about the culture of the target language country (traditions, life, national traits), and a source of motivation to master a foreign language speech activity. 
With regard to technology of the usage citation at the lesson, aphorism must conform to certain characteristics, namely:

- contribute new knowledge, to be informative;

- be brief, concise, consist of one phrase (expand aphorisms can be used as an epigraph to the lesson);

- be expressive in terms of phonetics and syntax that promotes easier memorization;

- contain a modern, general vocabulary;

- be picked up thematically and valid for use in educational purposes.

There are different kinds of work with aphorisms, such as: written communication, oral comment, brainstorm. Linguists have their own scheme of work with comments:

1) Determine the explicit and implicit meaning of the phrase, by analyzing keywords;

2) Identify the problem, the author, in the form of a question;

3) In response to a question, make a plan of reasoning (the idea is to be argued and illustrated with examples).

4) Directly answer the question.

Aphorisms can beincorporated in a huge amount of lesson exercises, which are divided into exercises that focus on working with the content of the aphorism, and exercises that focus on working with form and content together.

I. Work on the content:

- select aphorism illustrating morality tale;

- compose a story to illustrate this aphorism;

- Arguments "for" and "against" this aphorism.

II. Working with form and content:

- Open the brackets; put the verb in the appropriate time to aphorism acquired the desired meaning.

- Identify adjectives (nouns, adverbs, verbs) that characterize the various spheres of life;

- Pick cognates to this word;

- Select words related to one subject group;

- Pick up synonyms (antonyms) of the word.

Even weaker students are able to perform such tasks and to participate in the general work of the class.

For stronger groups tasks with semantic transformations can be offered, and the students must possess of good language competence. For example such a task: Transform the beginning (middle or end) of the classic aphorism so that it has acquired a new meaning. Similar exercise should be carried out by students at home, with the presence of time for reflection and preparation.

All proverbs are authentic and directly connected with real life people.

It should be noted that the communicative approach, which takes the leading position at the present stage, involves teaching grammar on interactive and functional basis, so proverbs rationally used to introduce certain new grammatical structures and forms, as well as during training exercises.

Noting lexical and grammatical saturation of proverbs and sayings, it can be argued that the maxims are illustrative material in the development of productive lexical skills on various topics, for example, on the topic «Knowledge»:

- Repetition is the mother of learning

- Knowledge is like money: the more he gets, the more he craves (Billings).

Or theme «Animals»:

- Busy as a bee.

- If you cut the woods, you'll catch the wolf.

Experience shows that, thanks to the original form of proverbs, concise, rhymed, new words easier to remember, and longer stored in memory. Students tend to include adages into their personal statements on a particular topic. 
J. Dobson argues that during the study of proverbs and sayings in a foreign language, people could better understand the mentality and comprehend native speakers, as proverbs reflect the culture, the history of this nation. Native speakers use proverbs in their speech very often (Dobson, 1987). In addition, working with proverbs and sayings promotes linguistic and contextual guesswork, because quite often the words included in the English proverb, translated into Russian sound completely different.

\section{Experiment}

For successful and effective implementation of the experiment in the control and experimental groups in 10 classes,first and foremost, we need to explore and take into account the age and psychological characteristics of learning activities of students learning at senior level at theEnglish lessons.Experiment is intended for 16 year-old students.Educators shouldpossess knowledge of the development of the psychological mechanisms of this developmental period in order to realize in every moment of work on what student's opportunities can count on and should not rely, and sometimes on the contrary must neutralize. Without this knowledge, a teacher can lose important tools of influence on the personality and activities of students.

The age-specific peculiarity of 16 year-old students is distinguished by the following: it affects all aspects of teaching and school life of high school students. As for a foreign language, its peculiarity influences, in particular, on their attitude to it as an academic subject, predetermine their ability in mastering different aspects of it, and the inclination, electoral interests, evaluation of educational activity in the classroom.

What is necessary to emphasize for the foreign language teachers at the age characteristics of high school students for the correct orientation of their teaching activities?

Upper-grade students are a product of modern life, it is complex, interesting and controversial.

Thinking of senior pupil acquires personal and emotional character.

Appointment of this period in life of every person is to expand the horizons of knowledge of the real world, other people and yourself, to develop own attitude, to find his place in society and to identify tasks of life. Hence, the interest of youth arises to the general, universal laws of nature and of human life, the desire to comprehend the theoretical and methodological foundations of scientific disciplines, a keen interest in the knowledge of human capabilities and man's inner world, the tendency to self-awareness and self-esteem.

A student of senior school does not just build an overall picture of the world, but produces its own attitude to everything that he knows and observes. Therefore, his mental activity combined with analyzing activity, propensity for reasoning and sensibility are especially intrinsic.

Central psychological process adolescence is the development of self-awareness. On the basis of the emerging consciousness of self-identity occurs high school student, a particular manifestation of which is a professional self-determination. It is not coincidence that the theme of integrated lesson using quotes in the experimental group was the theme «Work».

Senior student is distinguished by future reference, its expectation and premonition. In order to choose a profession, he must relate their capabilities with the requirements that apply to man of this profession. The proximity of the entry into the world of adult influences on the behavior of students, manifesting itself in particular in their community programs and in increasing demands for themselves and others.

Senior student passed the era of teenage crises and conflicts. At this age, there are improvements in communication and overall emotional well-being of the individual, large differentiation of his emotional reactions and ways of expressing emotional states, increased self-control and self-regulation.

Becoming of socially active position of the individual senior student goes on in every moment of his school life and learning, and is determined, in particular, by the norm established by the relationship and the nature of communication. This can be fully applied to foreign language lessons. This is, in particular, the degree of individualization achieved in communication, ways of its regulation and control, subject and character of speech: monologues, dialogues being explored on the basis of its participants' positions in communication.

To achieve improvement of a foreign language, formation and enrichment of vocabulary students can prosper just realizing under the condition of formation of generalized methods of orientation in the semantic structure of the word. This makes it possible to anticipate the most unknown words on the basis of analyzing their form and context of relationships with other words. Systematization of paradigmatic analysis suggests synonyms, antonyms, homonyms, its thematic groups, especially word-conversion. With regard to the syntagmatic, it is characterized by the choice of words that have entered into various combinations to the word, as well as speech samples in accordance with situations. In this age of systematization, vocabulary is directly related to rote 
material and promotes the expansion and use of knowledge acquired in previous assimilated system.

As for grammar, here in the same way there is a need in repeating the grammar topics and an opportunity to compare the grammatical phenomena, define the scope of use and arrange them on the basis of the paradigmatic (verb forms, the system conjugations, declensions, etc.). Formation of such a generalized system is an essential prerequisite for the successful implementation of speaking.

It should be noted that this potential is realized only due rational, age-appropriate arrangementof this kind of speech activity. Considering the organization of communication, it comprises the theme, meaningful orientation, personal orientation.

Significant impact of the communication process on learning the English language can be explained by its unique role in the lives of senior school students. They are impressed by the organization of communication in the classroom when there is a comparison of alternative approaches; the choice between the various points of view, defending his or her points of view, when there is a dispute. The excellent trigger to a deep emotional response from the student is to put him in front of such a problem, which makes it close to him and makes the student formulate his own conclusion.

The selection and organization of material, which involve the comparison of different opinions, attitudes, viewpoints, is possible in working with any maxim, proverb, because the same aphorism, one and the same adage can be interpreted differently depending on the submissions level knowledge, memory of the student. Discussion at the English lesson should always tactfully directed by the teacher. A great importance of the academic dispute occurring within certain rules, consists in the fact that preconditions for the formation of the culture of communication are produced, general communicativeskills are developed as the ability to understand the position of the opponent, tolerance to the opinion of another person, and the choice to protect his own opinion using the most suitable and vivid arguments. Under these conditions of self-expression of personality, a real problem speech and communicative motivation, initiative evolve and provide human involvement in communication.

Condition for the successful organization of such communication at the English lessons is personal individualization, which is based on the maximum tasks with elements of personal identity substructures of the individual student. Under personal individualization keeping the context of the student world is implied, his life experiences, desires, the scope of his interests, spiritual needs, emotional and sensual sphere and the status of the individual in the group. Therefore during the pedagogical experimentin the experimental groupeach lesson startedwith citations prepared by students (each lesson-different students), evoking response from students and stimulating their interest in the subject "English" because each student chooses that quotation that he is interested in, not what is required by the program. In addition, by the end of the year they will have a certain baggage of proverbs, aphorisms, which will make their speech richer and more expressive.

It is not coincidence that the first English lesson has been started with the following quotation: «Some people have thousands of reasons why they cannot do what they want to, when all they need is one reason why they can» (Mary Frances Berry), so that each student can ponder overwhether he has at least the only reason why he should learn English, whether he has the most important motivation in language learning. The students' answers were quite different, but they all agreed that when they are interested in a lesson, they are motivated. In our view, largely stimulated students' motivation depends on the teacher. Certainly, it is necessary to take into account the fact that the teacher must follow a certain program in accordance with state standards, but how to teach this material and in what ways to inspire students' interest is fully task of the teacher. A series of lessons with the use of citation as stimulating approach in training and learning activities of students at English lessons was proposed.

Research testing was conducted on the basisof school № 132 with advanced study of English in Kazan in subgroups 10 " $\mathrm{A}$ " that's experimental group and 10 " $\mathrm{B}$ " that accordingly is thecontrol group. In experiment a total of 26 people (in 10 "A"-13 students and in 10 "B"-13 students) were involved.

The objective of theresearch is to study the effect of the application of citation in formation the communicative competence of senior students at an English lessons.

In accordance with the hypothesis and objectives of the research plan of the experiment was developed, which consisted of three phases:
1) Diagnostic
2) Forming
3) Ascertaining 
The purpose of the diagnostic phase is to identify the level of students' knowledge of aphorisms, proverbs and sayings.

Objectives: To carry out a control test and identify the experimental results.

At the diagnostic phase classes of the experimental group as 10 "A" class and accordingly as a control group of 10 " $\mathrm{B}$ " were selected. To identify the level of students' knowledge of aphorisms, proverbs and sayings test on a selected topic in both classes was drafted and proposed. This test included 10 questions with one correct answer choice of the three proposed.

Obviously, because of certain circumstances, namely, firstly, the subject was not familiar, and secondly, lack of a high level of knowledge of the language and rich vocabulary of the selected items of certain proverbs and aphorisms, students in both groups coped satisfactorily with the test.

Table 1. Factor analysis with percentage in 10 "A", level ofquotations' knowledge

\begin{tabular}{lllll}
\hline Number of Students & Low & Below the average & Medium & High \\
\hline 13 & $1(8 \%)$ & $8(61 \%)$ & $4(31 \%)$ & 0 \\
\hline
\end{tabular}

Table 2. Factor analysis with percentage in 10 "B", level of quotations' knowledge

\begin{tabular}{lllll}
\hline Number of Students & Low & Below the average & Medium & High \\
\hline 13 & $4(31 \%)$ & $6(46 \%)$ & $3(23 \%)$ & 0 \\
\hline
\end{tabular}

Then research work on selection of quotes on the subject «Work» has been conducted, since this topic at this stage is very crucial, because most of the students are already thinking about the future self-determination and choice of the future profession. We have compiled a series of exercises for students of the experimental group in order to develop communicative competence and incorporation of these exercises in a series of lessons on the topic «Work».

On the forming stage of the study a series of lessons with the inclusion of functional-communicative tasks using aphorisms, proverbs on the theme «Work» were carried out.

The purpose of this stage: approbation of the citation as stimulating means in training and learning activities of students at an English lesson.

Tasks of the formative stage:

1) To check in a practical way possible use as a means the citation aimed at the development of the communicative skills of senior students.

2) To analyze the impact of this technique as a means of formation the motivation in language learning.

3) To shape an ability of students to exercise autonomy and creativity.

In every lesson various exercises to develop language and speech competence by using the technique of citation were included, which is an inseparable part of the communicative competence. Thus, switching to a variety of activitiesprevented students from fatigue, overexertion.

A first task was aimed at enhancing vocabulary and formation of communication skills. Suitable aphorisms of John D. Rockefeller were selected and students were encouraged to find in these aphorisms human qualities necessary for successfulwork, and qualities, on the contrary that hinder success. Furthermore, after successful completion of the task, students were encouraged to discuss the questions: what qualities contribute most to the success and what qualities the students themselves would be able to add to this list. Students shared their views actively using new vocabulary, studied on the basis of aphorisms, namely: perseverance, opportunism, thrift, singleness of purpose, inventiveness: ingenuity; resourcefulness and etc.

Noting that students often make in their speech glaring elementary mistakes: they forget the ending 3-person singular in thepresent tense, forget about the discrepancy between uncountable and countable nouns in English and Russian languages (e.g., knowledge in English is singular), at the next lesson, we proposed a task whichconsisted of finding grammarmistakes in proverbs and their correction. This does not only make the students remember all the rules learned by activating their mental activity, but also allows each student to feel as a teacher, thus removing 
tension and allowing the student to immerse fully in the exercise. Of course, grammar rules should be brought to automatism students to apply these rules in practice.

Functional-communication tasks contribute mostly to the formation of communicative competence, thus, we tried to introduce this type of tasks at every lesson, such as the restoration of the logical sequence of words in proverbs and sayings, and then selection of their equivalents in Russian.

In addition, communication tasks of another type were proposed, to find the correlation between the situation and the proverb or saying. This task has caused particular response from the students. Everyday situations were given and students had to analyze them and come to the conclusion what proverb is the most appropriate in this case, give the reason. In addition, the task had an appeal of students, because it required also real-life examplesfrom their own experience.

Moreover, we have developed an assignment based on the well-known aphorisms concerning theme «Work», the statement was read to students not completely, students have to come up with the end themselves. This assignment allowed to unlock the creative potential of the students, even the most timid and inactive students gladly participated. After all possible options proposed original version of aphorism was read. There was a discussion whose version was better.

All of the above-mentioned exercises were introduced in school № 132 with advanced study of English in Kazan. We believe that with the introduction of assignments using citation an English lesson becomes more aimed at the formation of communication skills. These tasks contribute to the formation of student's heightenedincentive to the subject. The process of working on the aphorisms, proverbs and sayings reveals students'creativity, contributes to the development of logic, communication and speech abilities. The form of these lessons is interesting and original. Epigraph to the lesson (aphorism) supports students' attention. The usage of proverbs and aphorisms atthe English lessons improves cognitive interest, the development of the students' imagination, speech and attention.

During the formative stage of the experiment a comprehensive lesson on using citation was conducted in the experimental group. (The theme («Quotations of Steve Jobs» was chosen in accordance with the interests of students).

To create a more intimate contact for group work we arranged tables opposite to each other, so that students can freely exchange views within the group. Homework prior to this lesson comprisedbringing the most favorite quote of Steve Jobs and comment it.

Students of the above-mentioned group wereenthusiastic in preparing their presentations and selection of quotations; there are a couple of examples of them:

$\checkmark \quad$ My favorite things in life don't cost any money. It's really clear that the most precious resource we all have is time.

$\checkmark$ Technology is nothing. What's important is that you have a faith in people, that they're basically good and smart, and if you give them tools, they'll do wonderful things with them.

Then discussion evolved in the form of a lively dialogue. Opinions were divided, completely different perspectives on certain statements were offered, but, nevertheless, the participants in the discussion were respectful of the views different from their own. Students gave enough convincing arguments in defense of their opinions, real life examples.

Thereupon students are encouraged to another type of work - listening, attentive listening to the Stanford commencement speech by Steve Jobsand writing the most memorable and favorite quotations.

Listen to the audio evoked response and interest of students; they expressed their opinions about Steve Jobs' speech and read their favorite quotations. As a generalization, students were asked: What theme are they devoted to? (Work, Life) so, what proverbs and sayings can you recollect connected with these two vital themes: work and life?

In conclusion, we proposed a task on the cards for the entire experimental group. The task was expressing their opinion on the choice of the future profession (to determine whether the students are ready with their choice, and if so what choice they have made).At the end of the lesson, we were able to reach a consensus, the quote of Steve Jobs has been written on the board as the outcome of the lesson: «Your work is going to fill a large part of your life, and the only way to be truly satisfied is to do what you believe is great work. And the only way to do great work is to love what you do».

It should be noted that students were active and vividly reacted to proposed assignments. Citation offers great 
opportunities for an active oral practice of each individual student, as was observed in the integrated lesson.

\subsection{Results}

Completing the forming stage of the experiment, the effectiveness of the work was tested, spending ascertaining step, which allowed summarize research.

Objectives of this stage:

1) To prove efficiency of citation at the English lessons in the formation of communicative competence.

2) Make a comparative analysis of the two groups and ascertain the diagnostic stages of the experiment.

This step was repeated in conducting pilot cut in both groups, which, after investigation and processing of the results showed the brightest contrast between the control and experimental groups. The experimental group, which carried out testing of citation as stimulating admission to training and learning activities of students at the English lesson, and in particular a series of lessons with the phased implementation of citation, as well as a comprehensive lesson on the theme: «Quotations of Steve Jobs» can be characterized by increase of motivation of students, indicator of the level of knowledge of aphorisms, proverbs increased significantly, moreover, communication skills improved, to the final lesson, students were able to express their points of view freely, to use aphorisms, proverbs in their speech, while in the control group, in which this technique was not tested, the result remained virtually unchanged, i.e. indicator of the level of students' knowledge remained at zero, and respectively there were no premises in motivation to learn the language.

Table 3. Results of proficiency inquotations" use after pedagogical experiment in 10 " $\mathrm{A}$ "

\begin{tabular}{lllll}
\hline Number of Students & Low & Below the average & Medium & High \\
\hline 13 & 0 & 0 & $2(15 \%)$ & $11(85 \%)$ \\
\hline
\end{tabular}

Table 4. Results of proficiency inquotations' use after pedagogical experiment in 10 "B"

\begin{tabular}{lllll}
\hline Number of Students & Low & Below the average & Medium & High \\
\hline 13 & $4(31 \%)$ & $5(38 \%)$ & $4(31 \%)$ & 0 \\
\hline
\end{tabular}

\subsection{Discussion}

The experience shows positive changes, mainly in improvement of communication skills. At the end of the experiment, students directly related to the experimental group were able to express their opinion freely, arguing and using adages and vocabulary studied on the basis ofquotations. They give the students some confidence to use English freely in class. Experimentally proved that with the introduction of assignments using quotations the English lessons are more aimed at the formation of communication skills, the formation of heightened student motivation to the subject.

When students choose the subject matter themselves, unambiguously, there is an interest that allows students to be more liberated, to speak without fear of making mistakes. Thus, a positive result gives the right to assert that citation promotes motivation, development of communication and speech abilities of senior students, causing in students linguistic interest.

Nowadays in secondary schools, unfortunately, such tasks with the use of quotations are rarely given, especially at the senior stage of learning. However, experiment has shown that this technique develops independence, creativity, responsibility, and analytical skills of students, the ability to work in collaboration, and most importantly, offers a great opportunity for active oral practice of each individual student. Therefore, this technique can be successfully implemented in the process of learning English.

\section{Conclusion}

Currently, the teaching of foreign languages gives priority to the development of students' willingness and ability to carry out cross-cultural communication in a foreign language with native speakers. As one of the core competencies, which determines the success of the graduate, its competitiveness in the labor market and in society in general, is communicative competence.

Practical experience affirms the necessity of the use of such techniques and tools at the English lesson, which would promote the formation of communication skills, development of linguistic interest, and most importantly, 
students' motivation. From year to year, English teachers face with a range of important issues, such as lack of interest, motivation of students, fear to communicate in a foreign language. In our opinion, the use of citation, namely, aphorisms, proverbs and sayings at English lessons - an efficient wayto develop communicative abilities, maintain students' interest in English, to improve efficiency in the classroom, as they help to introduce an element of games and competitions in the process of language acquisition.

To sum up, the effectiveness of the use of citation at English lessons is substantiated, one of the advantages of this technique is that it can be used at different stages of the lesson and at all levels of education (elementary, middle, senior) with different levels of language training for students and everything just depends on the professionalism of the teacher in the selection and presentation of the material. On the one hand, quotations are an invaluable material, and on the other hand at the same time it is a means of learning English, the development and control of the whole complex of communication skills and abilities: vocabulary and grammar, speaking and writing, reading and listening. This rich authentic material that does not require adaptation meets the highest artistic demands.

The use of citation converts English lessons intoa kind of discussion research club, which solves interesting, meaningful and practically available to students questions. Thus creating the prerequisites for overcoming the previously listed contradictions between passive ability to perceive the text and the ability to understand and produce speech. Quotations are an integral part of the development of the communicative competence of students. They don't only develop memory, but also allow students to learn to select lexical items adequatelyand develop emotional expressiveness of speech.

Carried out experimental work has proved the correctness of the hypothesis that the use of citation at English lessons contributes to the formation of communicative competence, the development of linguistic interest, motivate students in learning and communicating in English. Thus, it can be argued that the objective of research, to identify and substantiate efficiency of citation at foreign language lessons, achieved, its task successfully executed.

\section{References}

Brinton, D., Snow, M., \& Wesche, M. (1989). Content-based second language instruction. Boston: Heinle and Heinle.

Dobson, J. M. (1987). Effective Techniques for English Conversation Groups. Washington D.C.: English Language Programs Division.

Edelsky, C. (1989). Bilingual children's writing: Fact and fiction. In D. Johnson, \& D. Roen (Eds.), Empowering ESL students (pp. 165-176). New York: Longman.

Freeman, D. E., \& Freeman, Y. S. (1989). Evaluation of second language junior and senior high school students in the whole language content classroom. In K. Goodman, Y. Goodman, \& W. Hood (Eds.), The whole language evaluation book (pp. 141-151). Portsmouth, NH: Heinemann.

Freeman, D. E., \& Freeman, Y. S. (1994). Between worlds: Access to second language acquisition. Portsmouth, NH: Heinemann.

Freeman, D. E., \& Freeman, Y. S. (1998). ESL/EFL teaching: Principles for success. Portsmouth, NH: Heinemann.

Gamberg, R., Kwak, W., Hutchings, M., \& Altheim, J. (1988). Learning and loving it: Theme studies in the classroom. Portsmouth, NH: Heinemann.

Halliday, M. A. K. (1984). Three aspects of children's language development: Learning language, learning through language, and learning about language. In Y. Goodman, M. Haussler, \& D. Strickland (Eds.), Oral and written language development research: Impact on the schools. Urbana, IL: National Council of Teachers of English.

Hymes, D. (1970). On communicative competence. In J. Gumperz, \& D. Hymes (Eds.), Directions in Sociolinguistics (pp. 35-71). New York: Holt, Rinehart and Winston.

Krashen, S. (1982). Principles and practice in second language acquisition. New York: Pergamon Press.

Larsen-Freeman, D. (1986). Techniques and principles in language teaching. Oxford: Oxford University Press.

Richards, J., \& Rodgers, T. (1986). Approaches and methods in language teaching: A description and analysis. New York: Cambridge University Press.

Scarcella, R., \& Oxford, R. (1992). The tapestry of language learning: The individual in the communicative 
classroom. Boston: Heinle and Heinle.

Snow, M., \& Brinton, D. (1997). The content-based classroom: Perspectives on integrating language and content. White Plains, New York: Longman.

Stryker, S., \& Lou Leaver, B. (1997). Content-based instruction in foreign language education. Baltimore: Georgetown University Press.

Swain, M. (1985). Communicative Competence: Some roles of comprehensible output in its development. In S. Gass, \& C. Madden (Eds.), Input in second language acquisition (pp. 235-253). Rowley, MA: Newbury House.

Widdowson, H. (1978). Teaching language as communication. Oxford: Oxford University Press.

\section{Copyrights}

Copyright for this article is retained by the author(s), with first publication rights granted to the journal.

This is an open-access article distributed under the terms and conditions of the Creative Commons Attribution license (http://creativecommons.org/licenses/by/3.0/). 